\title{
Long-term treadmill exercise attenuates tau pathology in P301S tau transgenic mice
}

\author{
Odochi Ohia-Nwoko ${ }^{1}$, Saghi Montazari ${ }^{1}$, Yuen-Sum Lau ${ }^{2}$ and Jason L Eriksen ${ }^{1 *}$
}

\begin{abstract}
Background: Recent epidemiological evidence suggests that modifying lifestyle by increasing physical activity could be a non-pharmacological approach to improving symptoms and slowing disease progression in Alzheimer's disease and other tauopathies. Previous studies have shown that exercise reduces tau hyperphosphorylation, however, it is not known whether exercise reduces the accumulation of soluble or insoluble tau aggregates and neurofibrillary tangles, which are both neuropathological hallmarks of neurodegenerative tauopathy. In this study, 7-month old P301S tau transgenic mice were subjected to 12-weeks of forced treadmill exercise and evaluated for effects on motor function and tau pathology at 10 months of age.

Results: Exercise improved general locomotor and exploratory activity and resulted in significant reductions in fulllength and hyperphosphorylated tau in the spinal cord and hippocampus as well as a reduction in sarkosyl-insoluble AT8-tau in the spinal cord. Exercise did not attenuate significant neuron loss in the hippocampus or cortex. Key proteins involved in autophagy - microtubule-associated protein 1A/1B light chain 3 and p62/sequestosome 1 -were also measured to assess whether autophagy is implicated in the exercised-induced reduction of aggregated tau protein. There were no significant effects of forced treadmill exercise on autophagy protein levels in P301S mice.

Conclusions: Our results suggest that forced treadmill exercise differently affects the brain and spinal cord of aged P301S tau mice, with greater benefits observed in the spinal cord versus the brain. Our work adds to the growing body of evidence that exercise is beneficial in tauopathy, however these benefits may be more limited at later stages of disease.
\end{abstract}

Keywords: Tau pathology, Exercise, Alzheimer's disease, Neurodegeneration

\section{Introduction}

More than 35 million people worldwide are affected by dementia [1], with the leading cause being Alzheimer's disease (AD), primarily affecting those aged 65 years or older [2]. Central nervous system (CNS) accumulation of hyperphosphorylated tau and amyloid-beta proteins are pathological hallmarks of $\mathrm{AD}$, whereas tau accumulation also occurs in other tauopathies such as frontotemporal dementia (FTD), Pick's disease (PiD), progressive supranuclear palsy (PSP) and corticobasal degeneration (CBD). These diseases are all characterized by the intraneuronal or glial accumulation of neurofibrillary tangles (NFTs),

\footnotetext{
* Correspondence: jeriksen@central.uh.edu

'Department of Pharmacological and Pharmaceutical Sciences, University of Houston, 521 Science and Research Building 2, 4800 Calhoun Road, Houston, TX 77204, USA

Full list of author information is available at the end of the article
}

which are comprised of hyperphosphorylated and aggregated tau protein [3-5]. There are no approved treatments for diseases with only tau inclusions [6], whereas the currently approved drugs for $\mathrm{AD}$ temporarily relieve symptoms without altering disease progression [7].

Given the prevalence of these disorders, there is significant scientific and clinical interest in developing new approaches that can be used to prevent disease onset and to attenuate disease progression. Clinical studies suggest that being physically active later in life may be neuroprotective by preserving cognition [8-11], increasing neurotropic factors [12,13], and maintaining the structural integrity of the brain $[14,15]$. Additionally, the neuroprotective benefit of physical exercise has been demonstrated in patients as well as in animal models of

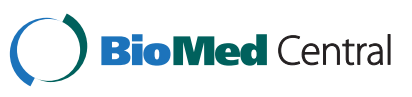

(C) 2014 Ohia-Nwoko et al.; licensee BioMed Central Ltd. This is an Open Access article distributed under the terms of the Creative Commons Attribution License (http://creativecommons.org/licenses/by/4.0), which permits unrestricted use, distribution, and reproduction in any medium, provided the original work is properly credited. The Creative Commons Public Domain Dedication waiver (http://creativecommons.org/publicdomain/zero/1.0/) applies to the data made available in this article, unless otherwise stated. 
AD. Slower declines in the activities of daily living score [16] and measures of functional independence [17], in addition to improvements in cognitive function [18], have been reported in AD patients subjected to aerobic and/or anaerobic forms of exercise. In animal models of $\mathrm{AD}$, exercise has been reported to have a range of beneficial effects, such as a reduction in the build-up of amyloid beta (A $\beta$ ) plaques, soluble and fibrillar $A \beta$ peptides [19-21], and improvements in cognitive [19,22-24] as well as non-cognitive [25] behaviors. In addition to effects on $A \beta$ pathology, there is some evidence of exerciseinduced benefits in tauopathy. Steffen and colleagues reported a case of improved motor function and an attenuated rate of brain volume loss in a patient with CBD and PSP after 2.5 and 10 years of exercise [26,27]. In support of the clinical data, there is also evidence that exercise can alter soluble forms of tau phosphorylation and positively affect behavioral deficits in transgenic mouse models [28,29].

While much research has been devoted to understanding the mechanisms by which physical activity can reduce or prevent the pathological consequences of toxic $\mathrm{A} \beta$ accumulation in $\mathrm{AD}[19,22,23,30-36]$, the impact of exercise on the neurodegenerative process in tauopathy is not as well understood. It is known that forced treadmill exercise can decrease tau hyperphosphorylation in NSE/htau23 mice [28], however this model does not appear to develop neurofibrillary tangles or neurodegeneration [37]. There is also evidence that voluntary wheel running can reduce tau hyperphosphorylation in THYTau22 mice [29], but it is not known whether exercise can affect both soluble and sarkosyl-insoluble (or aggregated) forms of tau, which are also pathological hallmarks of tauopathies [4]. Reductions in tau could potentially occur by a number of mechanisms, but there is evidence that autophagy can be induced in the brain by treadmill exercise [38], and recent reports indicate that pharmacological activation of autophagy via trehalose [39] or rapamycin [40] reduces soluble and insoluble tau aggregation in P301S mice. Based on these reports, we hypothesized that the induction of autophagy by exercise could play a role in reducing tau pathology.

In this study, we assessed whether long-term endurance treadmill exercise introduced after the onset of neurodegenerative tauopathy could improve general locomotor function and slow the development of tau neuropathology, possibly through inducing autophagy. Although there is evidence that short-term exercise is beneficial by increasing neurotrophic factors, cell proliferation and synaptic protein levels in the non-diseased rodent brain [41-44], long-term exercise has also been reported to produce similar benefits [45]. However, the effects of either shortor long-term exercise in diseased rodent models are more complex. Previous reports indicate that the benefits of exercise in $\mathrm{AD}$ mouse models depend on the duration and type of exercise protocol. For example, short-term, voluntary (wheel-running) exercise did not have a significant impact on $A \beta$ pathology after 3 to 4 weeks [46-48] or 6 weeks [49] of training. Conversely, 3-, 5- and 6-months of voluntary exercise reduced pathology (tau or $A \beta$ ) in THY-Tau22 [29], TgCRND8 [19] and 3xTg-AD [50] mice, respectively. Forced treadmill exercise is beneficial after short and long periods of training, as 4 weeks of exercise reduced A $\beta$ pathology in APP/PS1 mice [47], and 3 months of exercise reduced $\mathrm{A} \beta$ or tau pathology in NSE/PS2 [35] and NSE/htau23 [28,51] mice. Based on this prior evidence, for the present study we chose to introduce P301S tau transgenic mice-which overexpress the P301S-mutant human tau associated with clinical cases of neurodegenerative tauopathy [52] - to a 12-week forced treadmill exercise regimen that has been reported to benefit a Parkinsonian mouse model of neurodegeneration $[53,54]$.

\section{Results \\ Exercise increases general locomotor and exploratory behavior in P301S mice}

To assess whether introduction of treadmill exercise could affect animal locomotor activity and exploratory behavior, P301S tau transgenic mice and matching non-transgenic counterparts were tested in the open field. Exercise training resulted in enhanced total exploratory activity in P301S mice. Two-way analysis of variance (ANOVA) revealed a main effect of exercise, $[F(1,32)=8.1829$, $\mathrm{p}<0.01]$. Newman-Keuls post-hoc indicated that the transgenic exercised ( $\mathrm{Tg}$-EX) mice had significantly higher total activity versus the transgenic sedentary (Tg-SED) mice $(\mathrm{p}<0.01$; Figure 1A). We also observed a significant main effect of exercise in total distance traveled, $[\mathrm{F}(1,32)=$ 5.6585, $\mathrm{p}<0.05]$, where Tg-EX mice traveled more than Tg-SED mice $(\mathrm{p}<0.05$; Figure $1 \mathrm{~B})$, and ambulatory activity $[F(1,32)=7.9197, \quad p<0.01]$, where Tg-EX mice displayed increased ambulation versus Tg-SED mice $(\mathrm{p}<$ 0.05; Figure 1C). Exercise-enhanced locomotor behavior in $\mathrm{Tg}$-EX mice was not attributed to either rearing activity, $[F(1,32)=0.2072, \mathrm{p}=0.652]$ (Figure 1D) or stereotypic activity, $[\mathrm{F}(1,32)=0.0573, \mathrm{p}=0.812]$ (Figure $1 \mathrm{E}$ ). Additionally, increased locomotor and exploratory activity of Tg-Ex mice was not due to decreased anxietylike behavior, as all groups spent a similar amount of time in the center of the testing chamber, $[F(1,32)=$ $0.1514, \mathrm{p}=0.700$ ] (Figure $1 \mathrm{~F}$ ). There were no significant differences in locomotor or exploratory performance between the non-transgenic exercised (NTg-EX) and non-transgenic sedentary (NTg-SED) groups in total activity $(\mathrm{p}=0.446$; Figure $1 \mathrm{~A})$, total distance traveled $(\mathrm{p}=$ 0.542; Figure $1 \mathrm{~B})$, and ambulation $(\mathrm{p}=0.494$; Figure $1 \mathrm{C})$. 
A

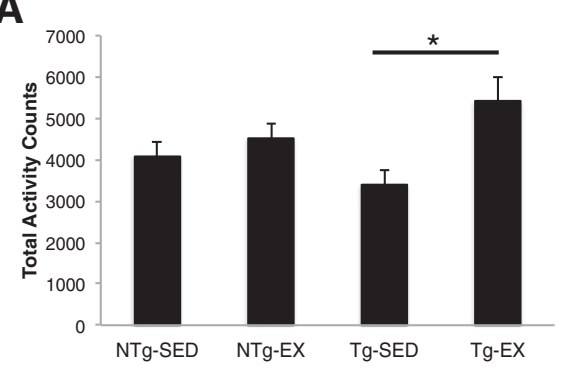

C

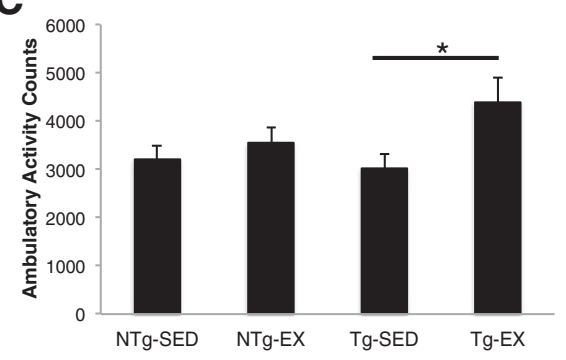

E

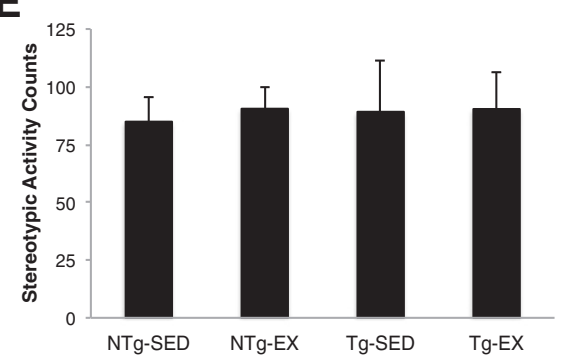

B

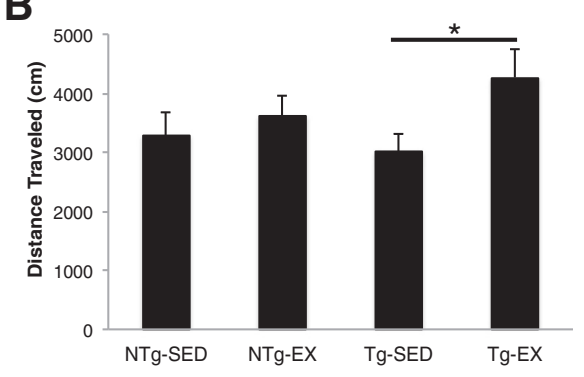

D

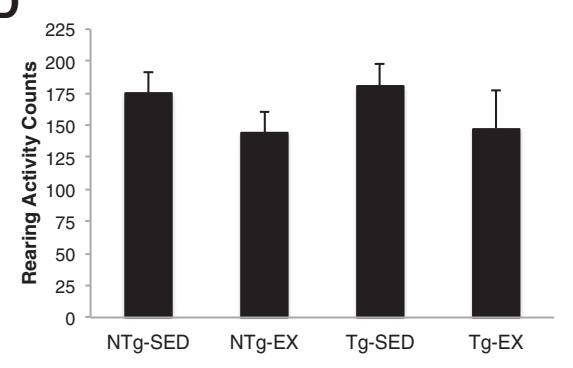

$\mathbf{F}$

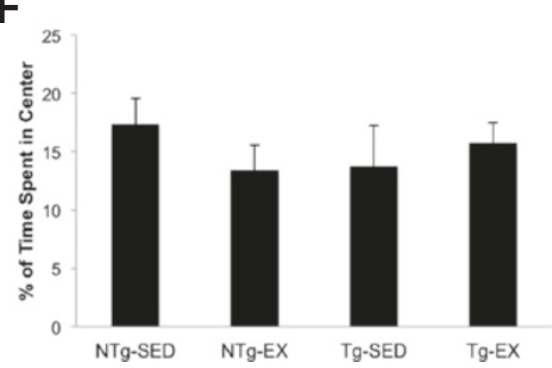

Figure 1 Open-field locomotor performance enhanced in P301S transgenic mice after 12-weeks of forced treadmill exercise. Transgenic exercised mice ( $\mathrm{Tg}$-EX) showed locomotor improvements in total activity (A), total distance traveled (B), and ambulatory activity (C) when compared to transgenic sedentary mice (Tg-SED). No significant changes were observed in rearing (D), stereotypic activity (E) and time spent in the center (F). [NTg-SED $(n=10), N T g-E X(n=8), \operatorname{Tg}-\operatorname{SED}(n=6), \operatorname{Tg}-\operatorname{EX}(n=8)] .{ }^{*} p<0.05=\operatorname{Tg}-\operatorname{SED}$ vs Tg-EX. A two-way ANOVA with the Newman-Keuls post-hoc was used to detect statistically significant differences.

Exercise training reduces total and hyperphosphorylated tau immunofluorescence in P301S mice

We used a Student's t-test to compare Tg-SED and Tg-EX groups and observed a significant reduction in total (TAU5) and phospho-tau immunofluorescence in the spinal cord ( $\mathrm{p}<0.05$; Figures 2 and $3 \mathrm{~A}$ ) and hippocampus ( $<<0.05$; Figures 2 and $3 \mathrm{C}$ ) of Tg-EX mice (Figure 3A,C) after exercise. Tau phosphorylated at sites Ser202 and Thr205 (AT8) was also significantly reduced in the spinal cord ( $<0.05$; Figure $3 \mathrm{~A})$ and hippocampus $(\mathrm{p}<$ 0.05 ; Figure $3 \mathrm{C}$ ), in the Tg-EX mice. Additionally, a significant reduction in tau phosphorylated at sites Thr212/ Ser214 (AT100) and Thr231 (AT180) was observed in the spinal cord $(\mathrm{p}<0.05$; Figure $3 \mathrm{~A})$, while a reduction in AT180 in the hippocampus almost reached statistical significance $(p=0.058$; Figure $3 C)$. No significant changes in total and phosphorylated tau were observed in the cortex (Figures 2 and $3 \mathrm{~B})$. When the CA1 and CA3 subregions were separately measured, exercise appeared to significantly reduce TAU5 immunofluorescence in the CA1 versus the CA3 of the hippocampus. We also observed marginal reductions in AT180 in the both sub regions after exercise (Figure 3D).

\section{Exercise has differential effects on soluble and insoluble} tau in the spinal cord and brain of P301S mice

In order to assess whether exercise could affect the levels of pathological tau, we performed sequential RIPA and sarkosyl-extractions to quantify levels of soluble and insoluble tau protein, respectively [55]. A Student's t-test was used to analyze differences between $\mathrm{Tg}$-SED and TgEX groups. We observed marginal reductions in total soluble tau protein in the spinal cord (45\% decrease), cortex (25\% decrease), and hippocampus (27\% decrease) in Tg-EX versus transgenic sedentary (Tg-SED) mice. (TAU5: Figure 4A, C and E). Total insoluble-tau protein 


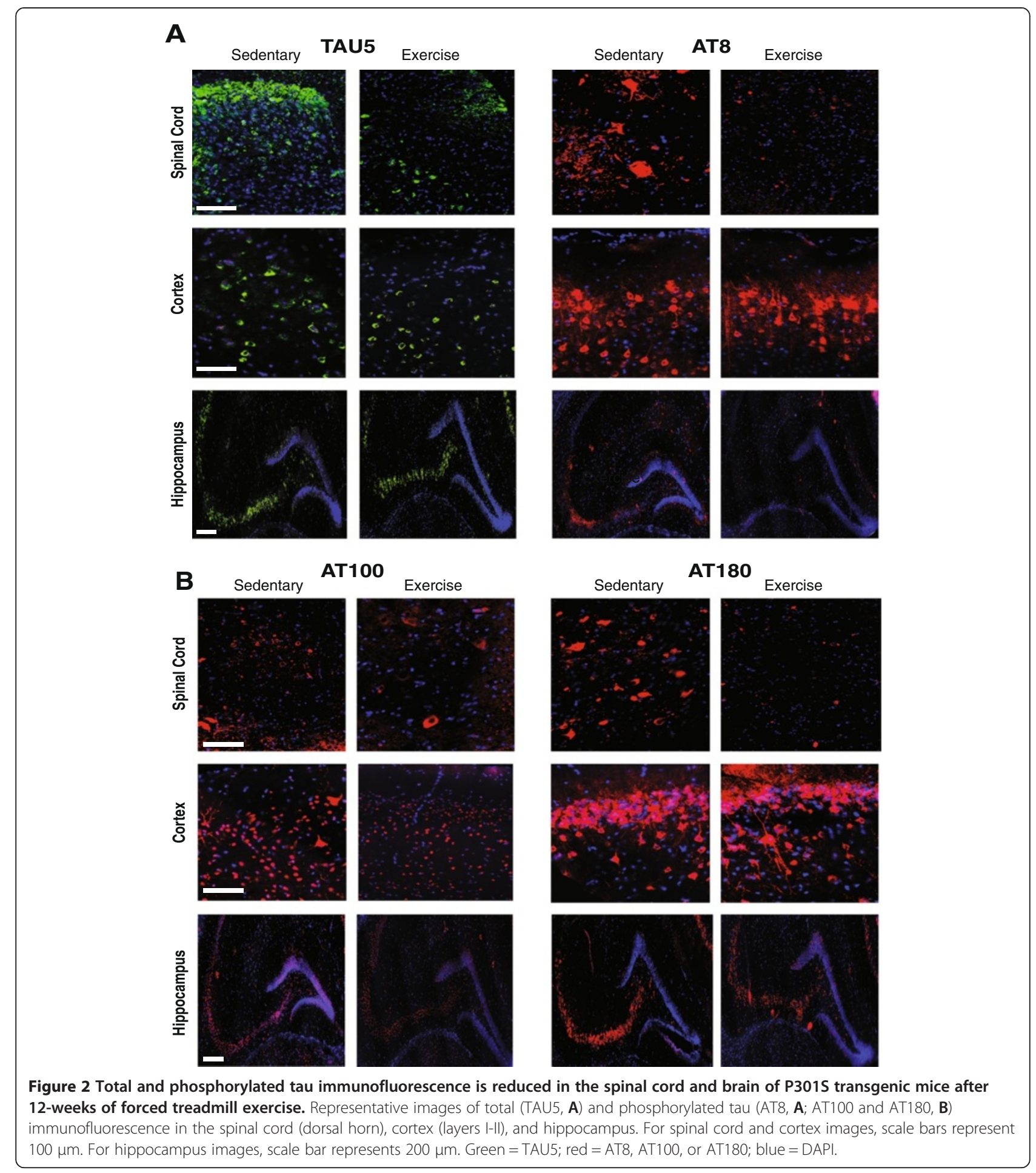

was also reduced in the spinal cord (76\% decrease) and cortex (41\% decrease) but not in the hippocampus (TAU5: Figure 4B, D and F) of Tg-EX versus Tg-SED mice. Soluble AT8-tau was reduced in Tg-EX versus Tg-SED mice in the spinal cord (35\% decrease) and cortex (40\% decrease), but not the hippocampus (Figure 4A, B and C); however, a significant reduction in insoluble AT8-tau was observed in the spinal cord ( $\mathrm{p}<0.05$; Figure 4B). No significant reductions in insoluble AT8-tau were observed in the cortex or hippocampus after exercise (Figure 4D,F). Exercise did not appear to significantly influence the levels of soluble and insoluble AT100-tau in the spinal cord of Tg-EX compared to Tg-SED mice (Figure 4A and B). In the cortex, we observed a $37 \%$ reduction in soluble AT100-tau and an 


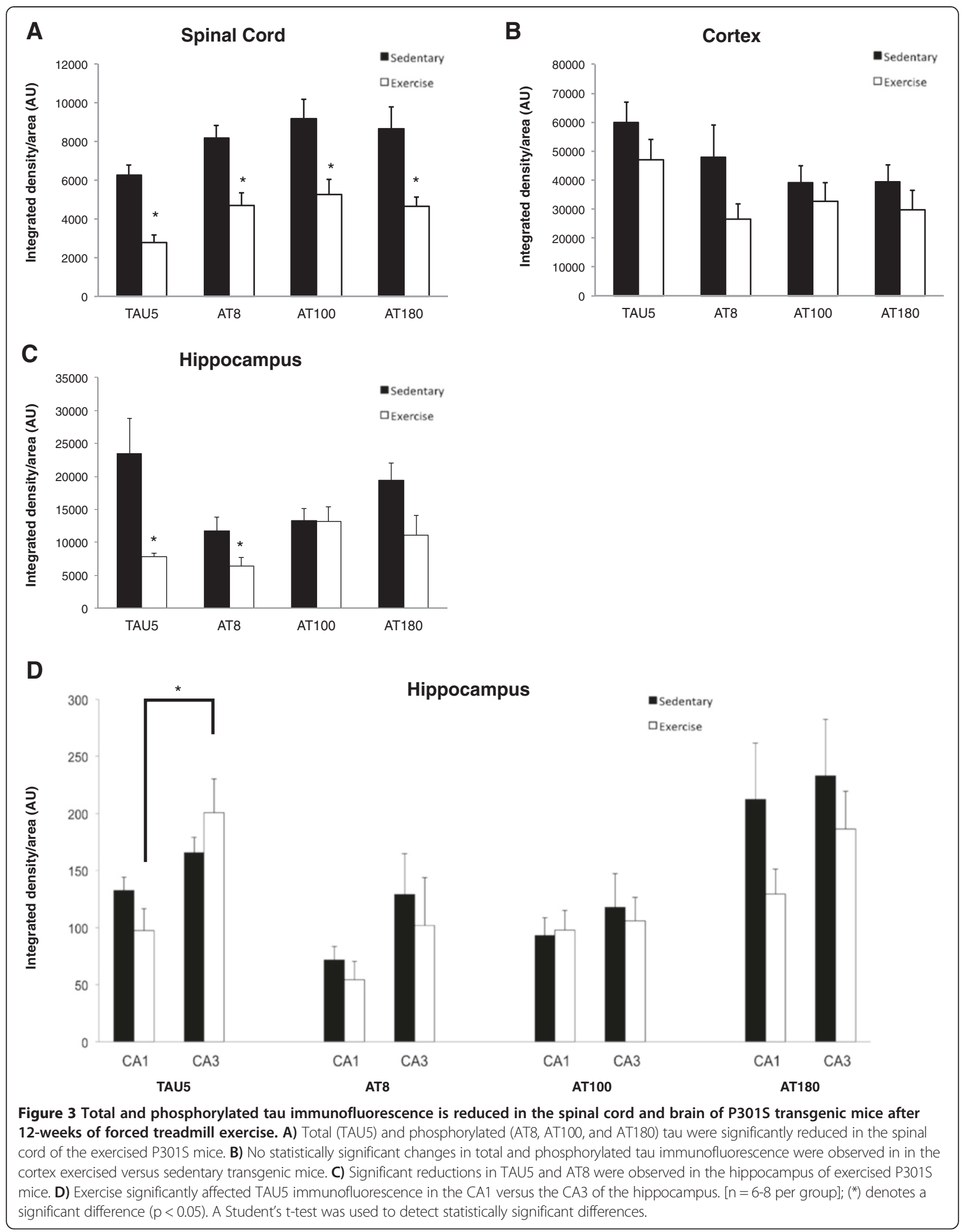




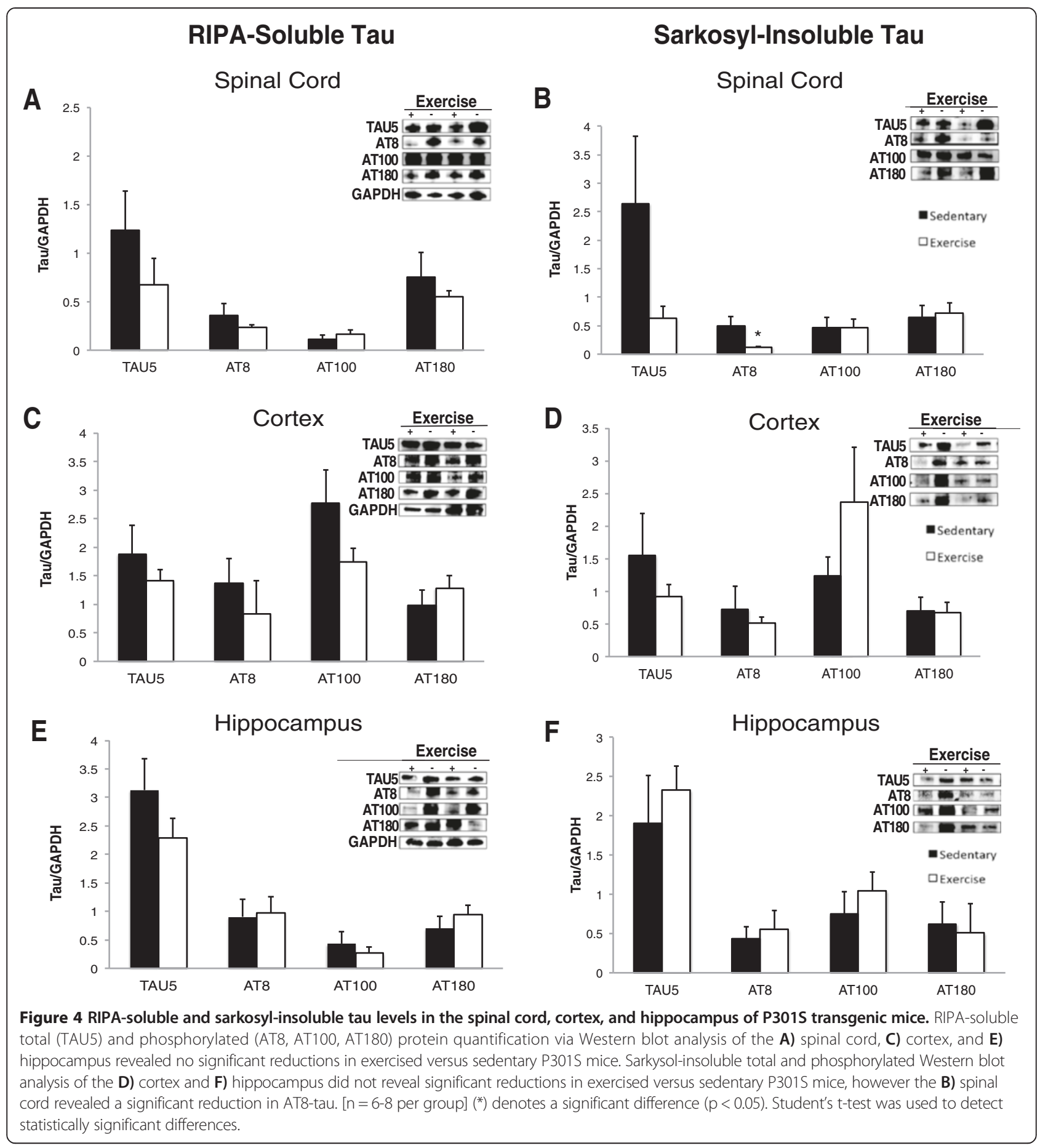

unexpected $48 \%$ increase in insoluble AT100-tau in the cortex of Tg-EX mice (Figure 4C,D). No significant reductions in soluble or insoluble AT100-tau were observed in the hippocampus (Figure 4E,F). We also did not observe any reductions in soluble or insoluble AT180-tau in the spinal cord, cortex and hippocampus of Tg-EX versus $\mathrm{Tg}$ SED mice (Figure 4A-F). Dot blot analysis revealed that exercise did not affect the levels of tau oligomers in any region; mice from the Tg-EX group displayed similar levels of oligomeric tau in the spinal cord, cortex and hippocampus (Figure 5A,C).

Exercise does not impact neuronal cell number in the spinal cord or brain of P301S mice

Quantification of motor neurons in the spinal cord revealed no significant difference in cell number between 


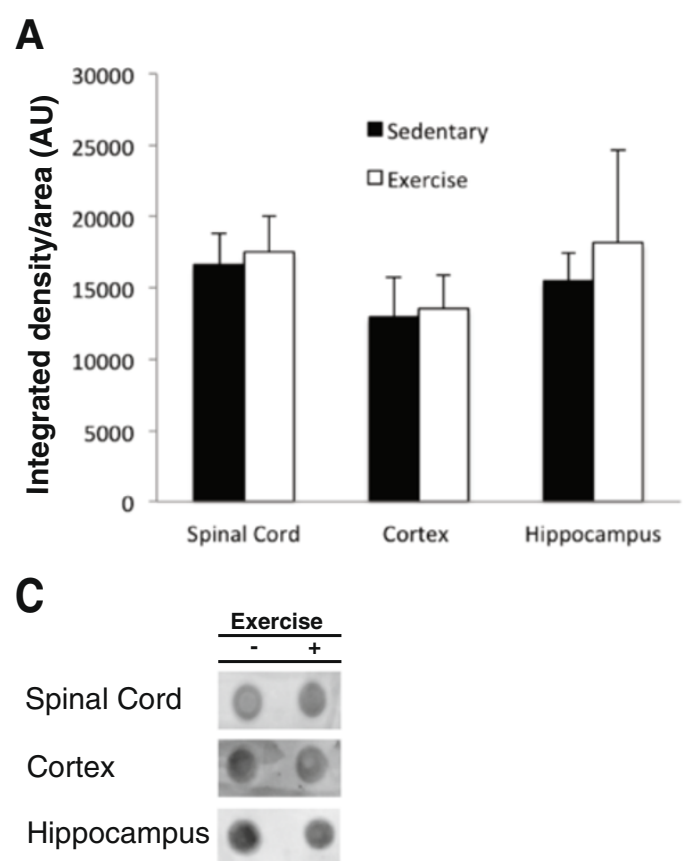

B

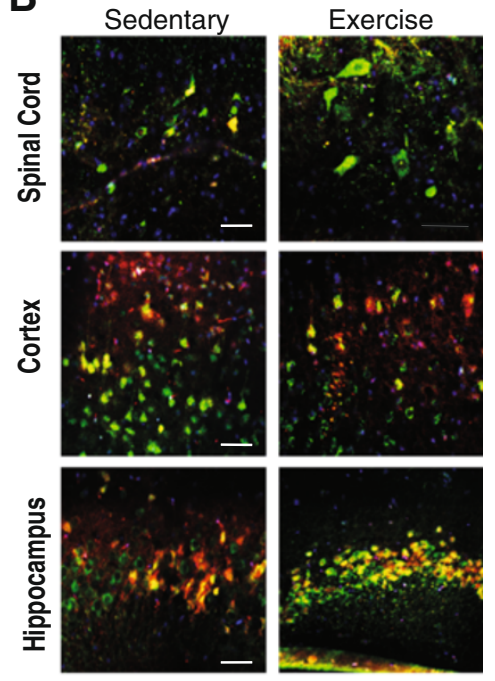

Figure 5 Soluble tau oligomers are present in the spinal cord and brain of P301S mice. A) Dot blot analysis indicates similar levels of oligomeric tau in the spinal cord, cortex, and hippocampus. B) Representative images of immunofluorescence of the spinal cord, cortex and hippocampus revealed similar T22 staining in sedentary versus exercised mice. Scale bar represents $50 \mu \mathrm{M}$ for all images. C) Representative dot blots of T22 in the spinal cord, cortex, and hippocampus. [N=4 per group]. Blue, DAPl; green, TAU5; red, T22. A Student's t-test was used to detect statistically significant differences.

all 4 groups, with two-way ANOVA indicating no main effect of genotype, $[F(1,28)=0.2212, p=0.642]$ or exercise, $[F(1,28)=0.8274, p=0.371]$ (Figure 6A). Cortical neurodegeneration was observed in P301S mice, with a main effect of genotype, $[\mathrm{F}(1,27)=27.8664, \mathrm{p}<0.01]$. Tukey's HSD post hoc revealed that the Tg-SED group had less NeuN-positive cells than the NTg-SED group $(\mathrm{p}<0.05$; Figure 6B). Similarly, the Tg-EX group had less NeuN-positive cells than the NTg-EX group $(\mathrm{p}<0.01$; Figure 6B). P301S transgenic mice displayed neurodegeneration in the cornus ammonis (CA) 3 of the hippocampus, with a main effect of genotype, $[F(1,24)=$ 41.5653, $\mathrm{p}<0.01]$. Tukey's HSD post hoc revealed that Tg-SED mice had significantly fewer NeuN-positive cells than NTg-SED mice $(\mathrm{p}<0.05$; Figure 6D) and the Tg-EX mice had fewer NeuN-positive cells than the NTg-EX mice ( $<<0.01$; Figure 6D). Neurodegeneration was also observed in the CA1 of the hippocampus of P301S mice $[F(1,27)=57.0844, p<0.01]$ with both TgSED and Tg-EX mice displaying significantly fewer NeuNpositive cells than their NTg counter parts $(\mathrm{p}<0.01$; Figure 6C).

\section{Exercise and autophagy-related proteins in P301S mice}

We did not observe any significant effects of exercise on protein levels of microtubule-associated protein $1 \mathrm{~A} / 1 \mathrm{~B}$ light chain 3-II (LC3-II) and p62/sequestosome 1 (p62/
SQSTM1) of the NTg versus Tg groups. A Student's ttest was used to compare differences between groups. In the spinal cord, protein levels of LC3-II $(\mathrm{p}=0.2380)$ and p62 ( $\mathrm{p}=0.1839)$ were not significantly different in NTg-SED versus NTg-EX mice (Figure 7). Similarly, no differences were observed in the cortex (LC3-II: $\mathrm{p}=$ 0.7610; p62: $\mathrm{p}=0.1607$ ) and hippocampus (LC3-II: $\mathrm{p}=$ 0.4773; p62: $\mathrm{p}=0.6878$ ) of NTg-SED versus NTg-EX mice (Figure 7). We also did not observe any significant differences in the spinal cord (LC3-II: $\mathrm{p}=0.2040$; p62: $\mathrm{p}=0.16901$ ), cortex (LC3-II: $\mathrm{p}=0.7037 ; \mathrm{p} 62: \mathrm{p}=0.5223$ ) and hippocampus (LC3-II: $\mathrm{p}=0.7632$; $\mathrm{p} 62$ : $\mathrm{p}=0.9497$ ) of Tg-SED versus Tg-EX mice (Figure 7 ). While not statistically significant, lower levels of both microtubuleassociated protein 1A/1B light chain 3-II (LC3-II) and p62/sequestosome 1 (p62/SQSTM1) were observed after exercise in non-transgenic mice. We did not observe strong LC3-I bands in the cortex and hippocampus (Figure 7A), which could be due to the greater sensitivity of the anti-LC3 antibody to LC3-II over LC3-I in some cases [56]. When probing for p62/SQSTM1 in the spinal cord, we observed lower levels in Tg-EX mice versus $\mathrm{Tg}$-SED mice and the presence of a stronger $37 \mathrm{kDa}$ band in the spinal cord, cortex, and hippocampus of transgenic versus non-transgenic mice (Figure 7D). The $37 \mathrm{kDa}$ band is known to be a product of caspase cleavage in vitro [57,58]. Additionally, we also observed the 


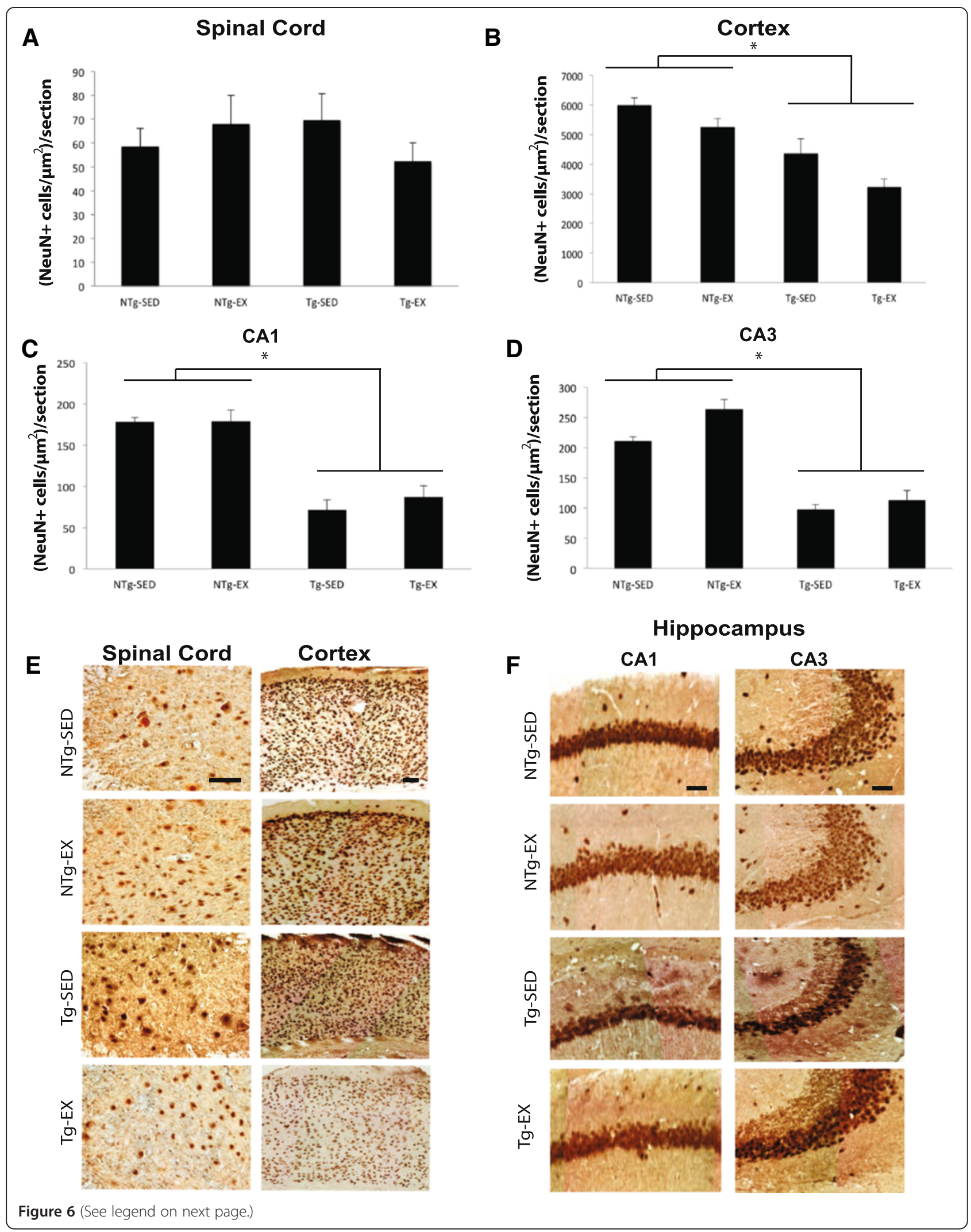


(See figure on previous page.)

Figure 6 Forced treadmill exercise does not affect neuronal cell counts in the spinal cord and brain. A) Spinal cord motor neuron counts were not significantly different across all groups. B) Transgenic mice displayed significant neurodegeneration in the cortex compared to non-transgenic controls. C) Transgenic mice displayed significant neurodegeneration in the CA3 of the hippocampus compared to non-transgenic controls. D) Transgenic mice displayed significant neurodegeneration in the CA1 of the hippocampus compared to non-transgenic controls. E) Representative images of the spinal cord and cortex. Scale bars represent $50 \mu \mathrm{m}$ for spinal cord and $100 \mu \mathrm{m}$ for the cortex. F) Representative images of the CA1 and CA3 subregions of the hippocampus. Scale bar represents $25 \mu \mathrm{m}$. [NTg-SED $(n=6), \mathrm{NTg}-\mathrm{EX}(n=8), \mathrm{Tg}-\mathrm{SED}(\mathrm{n}=6)$, Tg-EX $(n=8)]$; $\left(^{*}\right)$ denotes a significant difference $(p<0.05)$. A two-way ANOVA with the Tukey's HSD post-hoc was used to detect statistically significant differences.

presence of 25 and $20 \mathrm{kDa}$ bands in the spinal cords of transgenic mice, whereas these bands were not present in the non-transgenic mice (Figure 7D). Additionally, we observed accumulation of LC3-II and p62/SQSTM1 in the sarkosyl-insoluble fraction of the spinal cord, cortex and hippocampus of P301S mice (Figure 7E).

\section{Discussion}

Pathological tau and/or $A \beta$ accumulation occurs in Alzheimer's disease and other tauopathies. There are numerous reports that have focused on the exercise-induced reductions of $\mathrm{A} \beta$ pathology and behavioral impairments in animal models of Alzheimer's disease [19-25,32,34]. It has been reported that exercise can also reduce soluble hyperphosphorylated tau in mouse models of tauopathy $[28,29]$. In this report, we investigated whether longterm (12 weeks) forced treadmill exercise could attenuate or prevent the progression of tauopathy in mice that overexpress human P301S-mutated tau. The P301S mutation is associated with familial forms of FTD $[3,59,60]$, and is known to cause hyperphosphorylation, aggregation and filament formation of tau [61], which decreases the affinity of tau for microtubules and leads to subsequent neurodegeneration and the development of NFTs. P301S tau transgenic mice develop extensive tau pathology in the spinal cord at 6 months of age $[39,62]$ accompanied by neurogenic muscle atrophy [52], which results in a progressive decline in locomotor function. While our P301S mice had slightly lower activity in the open field, we did not observe a profound deficit in general locomotor and exploratory activity in our 10-month old P301S mice compared to the non-transgenic mice, potentially due to phenotypic drift that has been previously reported in this mouse line [63-65].

We observed significant tau pathology in our 10-month old mice and forced exercise training significantly enhanced locomotor and exploratory activity in Tg-EX versus Tg-SED mice. Our observations are in accordance with recent clinical evidence [26,27] showing that a patient diagnosed with CBD and PSP that participated in a regular exercise program (including treadmill training) for 10 years displayed reduced fall frequency, as well as improved balance and ambulation after exercise training [27]. The enhancement of locomotor ability we observed could be attributable to a variety of factors. We observed significant reductions in tau hyperphosphorylation and aggregation in the spinal cord, an indication that the progression of tau pathology was attenuated by exercise. Hyperphosphorylation and aggregation of tau are associated with synapse loss [52] and altered synaptic function [66] in P301S mice, so it is possible that treadmill exercise prevented these alterations in the spinal cord, restoring adequate neurotransmission at the neuromuscular junction. Treadmill exercise elevates the expression of synaptophysin and synapsin 1 [67-73], as well as post-synaptic density protein-95 $[68,74,75]$, supporting the notion that exercise enhances synaptic neurotransmission. A reduction in tau pathology via exercise could result in an increase in expression of synaptic proteins, or this increase could occur directly via forced exercise, resulting in enhanced synaptic transmission in the spinal cord and improved locomotor function.

Pre-neurofibrillary tangles are comprised in part, by pThr231 tau, while extracellular and intracellular neurofibrillary tangles (comprised of mostly filamentous tau) are stained with antibodies that recognize phosphorylation at sites Ser202/Thr205 (AT8) and Thr212/Ser214 (AT100) in Alzheimer's disease [76]. In our study, we observed reduced total and hyperphosphorylated tau in the lumbar spinal cord and hippocampus, showing a significant reduction of phosphorylated tau Ser202/Thr205 (AT8) in the spinal cord and hippocampus, and Thr231 (AT180) and Thr212/Ser214 (AT100) in the spinal cords of Tg-EX mice. These findings indicate that forced treadmill exercise attenuates the progression of neurofibrillary tangle formation in the spinal cord and reduces filamentous tau in the hippocampus of P301S mice. Our data are consistent with the results published by Leem and colleagues [28], who reported a reduction in AT8-positive immunoreactivity in the hippocampus after forced treadmill exercise in Tg-NSE/htau23 mice. However, our results are in contrast to that of previous studies using other mouse models of tauopathy, where a reduction in AT100 [29] and not AT8-positive immunoreactivity [29,77,78] was observed in the hippocampus after voluntary wheel running exercise. The differences in experimental outcomes could be attributed to different choices of exercise modality [79], where forced treadmill exercise maybe more beneficial in tauopathy versus voluntary exercise. Additionally, different choice of experimental mouse 
A

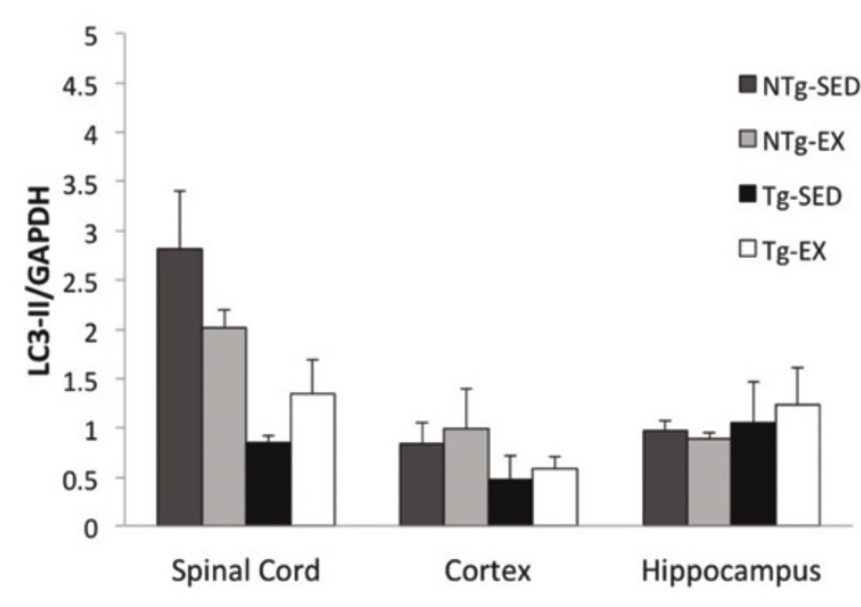

C

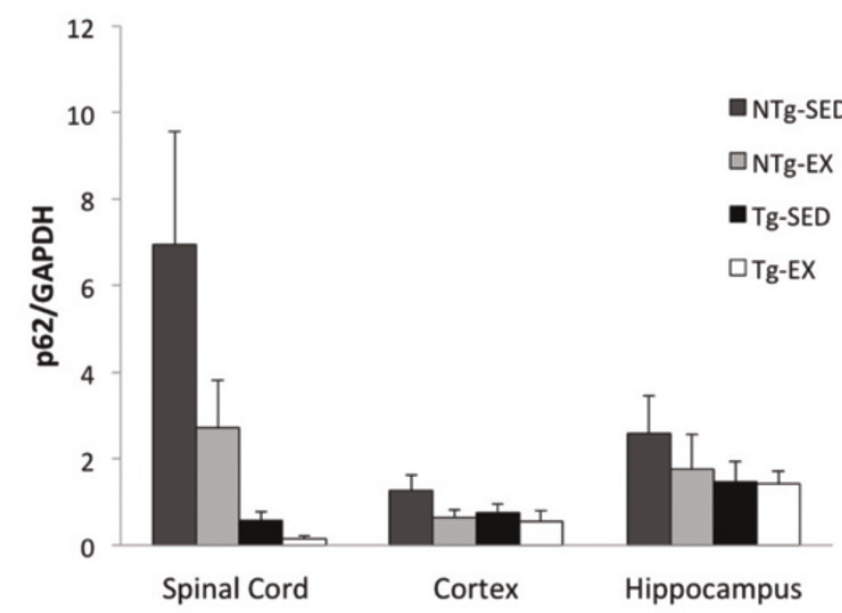

E

\begin{tabular}{|c|c|c|}
\hline & LC3-II & p62/SQSTM1 \\
\hline Exercise & & \\
\hline
\end{tabular}

Spinal Cord
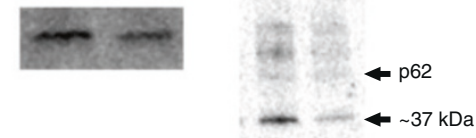

Cortex
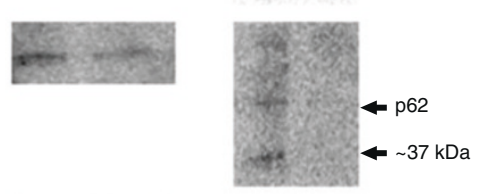

Hippocampus
B LC3

\begin{tabular}{cccccc}
\hline P301S & - & - & + & + \\
Exercise & - & + & - & + \\
\hline
\end{tabular}
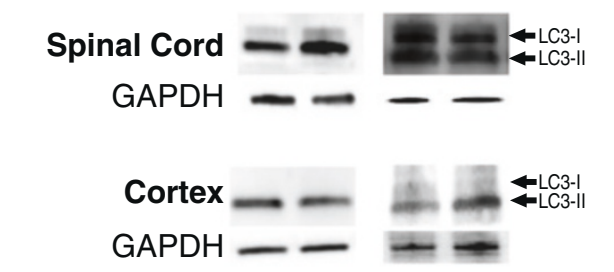

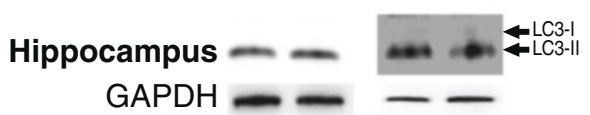

D

\section{p62/SQSTM1}

\begin{tabular}{ccccc}
\hline P301S & - & - & + & + \\
Exercise & - & + & - & + \\
\hline
\end{tabular}

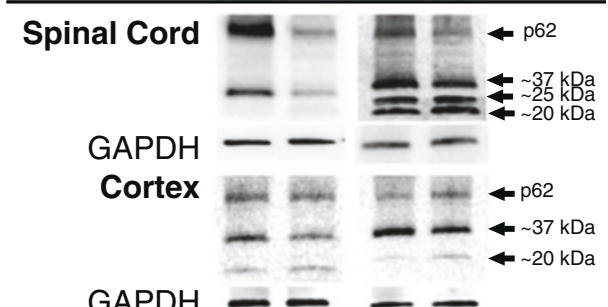

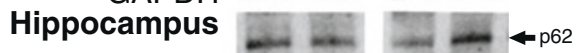

GAPDH - - - 
Figure 7 LC3-II and p62/SQSTM1 Western blot analysis. A) There were no significant effects of exercise on LC3-II levels in P301S or non-transgenic mice in the spinal cord, cortex, and hippocampus. [ $\mathrm{N}=3-4$ per group] B) Representative western blots of LC3-II. C) There were no significant effects of exercise on p62/SQSTM1 levels in P301S or non-transgenic mice in the spinal cord, cortex, and hippocampus. Intense 37, 25, and 20 kDa bands were observed in P301S mice, an indication of proteolytic cleavage. [N=3-4 per group] D) Representative western blots of p62/SQSTM1. E) Representative western blots of sarkosyl-insoluble LC3-II and p62/SQSTM1 in the hippocampus, cortex, and spinal cord.

model used in the present study versus the aforementioned reports could also be a source of the discrepancy in results.

Despite evidence that exercise can reduce tau hyperphosphorylation in mice $[28,29]$, it is not known whether forced treadmill exercise can reduce insoluble tau accumulation, which is a pathological characteristic of tauopathies [4]. To address this question, we analyzed RIPA-soluble and sarkosyl-insoluble forms of tau protein in the spinal cord and brain of P301S mice. Sarkosyl protein extractions are routinely used to isolate aggregated paired helical filaments of tau, which are the primary constituents neurofibrillary tangles [80]. While we observed marginal reductions in total tau for RIPA-soluble and sarkosyl-insoluble tau pools in the spinal cord, there was a significant reduction in sarkysol-insoluble AT8-tau, suggesting that forced treadmill exercise reduces filamentous tau accumulation. We observed only marginal reductions in soluble or insoluble tau protein in the hippocampus and cortex. These observations are similar to our histological data, where no significant changes in total or hyperphosphorylated tau were observed in the cortex as well as in AT100 and AT180 in the hippocampus. In addition to filamentous tau, we also analyzed the levels of soluble tau oligomers, which are thought to be toxic participants in neurodegenerative tauopathies [81,82]. We found that P301S tau mice express soluble oligomeric tau; however, exercise did not appear to significantly affect oligomeric tau levels in the brain and spinal cord.

Our results suggest that forced treadmill exercise reduces total and phosphorylated insoluble tau in the spinal cord, but only moderate changes occur in the brain. In accordance with these results, we observed a significant degree of cell loss in the hippocampus and cortex that was not alleviated by our exercise regimen. In the hippocampus, the CA1 and CA3 regions of P301S mice displayed neurodegeneration, which is consistent with previous reports in this mouse model $[52,77,83]$. Both hippocampal regions have extensive connections with the entorhinal cortex (EC) $[84,85]$, where significant tau pathology and cell loss is also observed [52]. Significant neurodegeneration in the CA regions could result from synaptic propagation of tau pathology from the EC [86,87] and/or degeneration of EC afferents [88,89]. Since the dentate gyrus (DG) also relies on its connections with the EC $[84,85]$, it is plausible that tau propagation from the DG to the CA3 (and the CA1 via the Schaffer collaterals), or deafferentation could also impact the neurodegenerative process in CA hippocampal regions.

Given that we did not see significant reductions in hippocampal and cortical soluble or insoluble tau in Tg-EX mice, neurodegenerative tau pathology in the hippocampus and cortex may have progressed to a stage that could not be mitigated with 12 weeks of forced treadmill exercise. Previous reports have suggested that forced treadmill exercise may not reverse or prevent some diseases [90,91] and in some cases can exacerbate disease progression $[92,93]$ possibly because of increased stress associated with the treadmill protocol. However, our exercise regimen did not appear to worsen tau pathology in the brains of P301S mice.

Neurodegenerative diseases are characterized by the accumulation of aggregated proteins, an indication that there is either increased production or inefficient elimination of dysfunctional or misfolded proteins that results in perturbed proteostasis. Both autophagy and the ubiquitinproteosome system have been implicated in abnormal protein accumulation associated with neurodegenerative processes $[94,95]$. Therefore, our final aim was to investigate whether autophagy is a possible mechanism by which tau pathology was mitigated by forced treadmill exercise. Autophagy activation is characterized, in part, by increased production of LC3-II and increased degradation of p62/SQSTM1[38,96] relative to baseline levels. We observed that P301S and non-transgenic mice introduced to forced treadmill exercise did not have significantly increased levels of LC3-II in the spinal cord and brain when compared to their sedentary counterparts. The levels of p62/SQSTM1 were marginally reduced after exercise in the spinal cords of both non-transgenic and P301S mice, while no changes were observed in the hippocampus and cortex; therefore, the reduced levels of p62/SQSTM1 we observed in the spinal cord of NTg-EX and Tg-EX mice could be an indication of autophagy induction. We observed significant reductions of insoluble AT8-tau in the spinal cord, which could be a result of degradation of tau aggregates by exercise-induced autophagy. In support of this notion, pharmacological activation of autophagy via rapamycin [40] and trehalose [39,97] reduces insoluble AT8-tau in P301S mice. In addition to aggregated tau, autophagy is also known to promote the degradation of several aggregated proteins associated with neurodegenerative disease, including $A \beta[98]$, huntington $[99,100]$, and alpha-synuclein $[100,101]$. However, we did not observe 
reductions in insoluble phosphorylated tau or p62/ SQSTM1 in the brain.

In this study, P301S mice displayed multiple lower molecular weight p62/SQSTM1 bands (37, 25 and $20 \mathrm{kDa})$ in the spinal cord. This observation is consistent with increased caspase or calpain cleavage $[57,58]$, which suggests that the P301S mutation could result in a selective disruption of the autophagic processes, potentially attributable to the loss of polyubiquitin- and LC3-binding regions of p62/SQSTM1 following proteolytic cleavage [57]. The loss of the polyubiquitin-binding region of p62/SQSTM1 may also disrupt proteasomal degradation of tau, as $\mathrm{p} 62 /$ SQSTM1 participates in the shuttling of ubiquitinated tau to the proteasome [102]. It has been hypothesized that impaired proteasomal degradation of soluble tau could lead to its toxic accumulation [103,104], thus impairment in the ubiquitin-proteasome system in P301S tau mice is also conceivable. Therefore, our observations are consistent with previous observations that disruptions in protein degradation systems may occur in neurodegenerative tauopathy [105], which is in line with previous reports of autophagy disruption in other neurodegenerative diseases [106-109].

Since exercise is known to produce a variety of positive changes in the CNS, we cannot exclude the possibility that other mechanisms may underlie the reductions in tau pathology we observed. Several types of exercise are known to increase the level of neurotrophins in the CNS, particularly, brain-derived neurotrophic factor (BDNF) [110-114], which increases neuronal survival and differentiation [115]. Elevated levels of BDNF also decrease tau phosphorylation via the PI3K-Akt pathway by decreasing

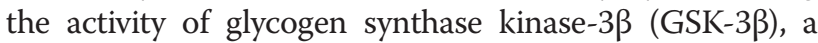
major tau kinase $[116,117]$. In the present study it is possible that exercise-induced increase in BDNF levels (and decreased GSK-3 $\beta$ activity) resulted in the attenuation tau phosphorylation we observed. Indeed, recent evidence suggests that forced treadmill exercise elevates the levels of inactivated phospho-GSK-3 $\beta$ in the brain $[74,118]$. This evidence supports an alternate mechanism by which exercise can modulate the progression of tau pathology, which warrants further investigation in future studies with P301S mice.

In conclusion, our work demonstrates that 12 weeks of forced treadmill exercise significantly attenuates tau pathology in the spinal cord and has moderate effects in the brains of older P301S tau mice, but that treadmill exercise does not prevent the progressive underlying neurodegeneration associated with tauopathy when introduced at later ages. Given that our results show exercise modulates tauopathy, our observations suggest that there may be a critical window whereby exercise can have the greatest impact on disease progression; the introduction of forced treadmill exercise before the development of severe pathology may be more beneficial. Our results also support the possibility for a role of autophagy in the exerciseinduced reduction of tauopathy, and that autophagy and/ or proteasomal dysfunction in P301S tau mice may contribute to the development of tau pathology.

\section{Materials and methods \\ Animals}

The P301S tau transgenic mouse expresses human tau (1N4R) with a P301S mutation [52]. These mice display progressive neurofibrillary tangle (NFT) pathology and neurodegeneration in the brain and spinal cord, developing lower-limb weakness around 6 months of age. P301S tau mice (7-8 months old), and their age-matched nontransgenic controls were individually housed in the animal facility at the University of Houston. Mice were housed in a climate-controlled room $\left(25^{\circ} \mathrm{C}\right)$ on a $12 / 12 \mathrm{~h}$ light/ dark cycle and given food and water ad libitum. All experiments were approved by the University of Houston Institutional Animal Care and Use Committee and implemented following the National Research Council's Guide of The Care and Use of Laboratory Animals.

\section{Forced treadmill exercise}

Mice were designated to four groups: exercised (Tg-EX) and sedentary (Tg-SED) P301S mice along with their non-transgenic exercised (NTg-EX) and sedentary (NTgSED) counterparts. Beginning at 7 months of age, mice ran on a six-lane motorized treadmill (Columbus Instruments, Columbus, OH, USA) 5 days/week for $40 \mathrm{~min} /$ day for 12 weeks. The mice in the exercise groups were trained on treadmill running with a speed up to $15 \mathrm{~m} / \mathrm{min}$ (5 min at $6 \mathrm{~m} / \mathrm{min}, 5 \mathrm{~min}$ at $9 \mathrm{~m} / \mathrm{min}, 20 \mathrm{~min}$ at $12 \mathrm{~m} /$ $\mathrm{min}, 5 \mathrm{~min}$ at $15 \mathrm{~m} / \mathrm{min}$, and $5 \mathrm{~min}$ at $12 \mathrm{~m} / \mathrm{min}$ ) with a $0^{\circ}$ inclination. All exercised mice ran $450 \mathrm{~m}$ per day with a total of $27 \mathrm{~km}$ for the 12 week duration of the study. This exercise protocol has been shown to produce cardiorespiratory and metabolic adaptations similar to those seen in humans while exercising $[53,54,119]$. The sedentary mice were brought to the exercise facility in order to expose these mice to the same conditions as the exercised mice. In order to ensure that all mice were able to complete the exercise protocol, mice were qualitatively evaluated throughout the duration of exercise trials.

\section{Open field activity}

Mice were tested $48 \mathrm{~h}$ after completion of 12 weeks of endurance treadmill exercise. Mice were placed in the center of a $60 \times 40 \mathrm{~cm}$ Plexiglas box and allowed to explore the area for $30 \mathrm{~min}$. Open field activity was measured in standard lighting conditions using a computer-operated Opto-Varimex Micro Activity Meter v2.00 system, as previously described [120]. Briefly, each Plexiglas testing chamber contained sensors with 8-infared light emitting 
diodes and 8 phototransistors that emit and detect infared light beams. Movement was detected by beam breaks, and the Opto-Varimex program recorded total activity counts, distance traveled, ambulatory activity counts, rearing activity counts and stereotypic activity counts.

\section{Tissue extraction}

Mice were sacrificed under carbon dioxide $\left(\mathrm{CO}_{2}\right)$ anesthesia and the brains and spinal cords were dissected. Each hemibrain and spinal cord was placed in Accustain (a proprietary formalin-free fixative from Sigma-Aldrich, St. Louis, MO, USA) for tissue fixation for 24 hours at $4^{\circ} \mathrm{C}$. After Accustain fixation, the hemibrain and spinal cord were stored in $70 \%$ ethanol at $4{ }^{\circ} \mathrm{C}$ for paraffin processing. The other half of each brain and the cervical spinal cord were snap frozen stored at $-80^{\circ} \mathrm{C}$ for biochemical processing. Tissues were homogenized in cold RIPA lysis and extraction buffer (Thermo-Fisher Scientific, Rockford, IL, USA) containing protease and phosphatase inhibitors. Samples were then centrifuged at 20,000 $\times g$ for $20 \mathrm{~min}$ at $4{ }^{\circ} \mathrm{C}$. The pellet was discarded, and a portion of the RIPA lysate was used for biochemical analysis. Sarkosylinsoluble tau was isolated following previous reports [55], with RIPA supernatants adjusted to $1 \%$ sarkosyl. Samples were incubated for $1 \mathrm{hr}$ at room temperature and then spun at $100,000 \times g$ at room temperature. The supernatants were discarded and the pellets were resuspended in $\mathrm{O}+$ buffer $(62.5 \mathrm{mM}$ Tris- $\mathrm{HCl}, 10 \%$ glycerol, $5 \%$ 2mercaptoethanol, 0.1\% SDS, phosphatase and protease inhibitors). Samples were then boiled for $3 \mathrm{~min}$ and kept at $-20^{\circ} \mathrm{C}$ for Western blot analysis.

\section{Immunofluorescence and image analysis}

Brain and lumbar spinal cord tissue was paraffin processed and sectioned at a $10 \mu \mathrm{m}$ thickness. Immunofluorescence was performed on the lumbar spinal cord and hemibrain sections using the TAU5 antibody (anti-TAU, 1:500, Invitrogen) that recognizes phosphorylated and non-phosphorylated tau and phospho-dependent antibodies: AT8 (anti-pSer202/Thr205, 1:500, Thermo Scientific), AT100 (anti-pSer212/Thr214, 1:500, Thermo Scientific), and AT180 (anti-pThr231, 1:500, Thermo Scientific). Additionally, double immunofluorescence with a subset of P301S mice ( $\mathrm{n}=4$ mice per group) with TAU5 (1:500) and the T22 antibody (1:200, kindly donated by Dr. R. Kayed), which specifically recognizes oligomeric forms of tau [121]. For image analysis, up to six equidistant sections were chosen per animal, corresponding to plates 42 to 49 in the brain [122] and L1 to L6 of the spinal cord [123]. Integrated density analysis was measured by a blinded observer with NIH Image J software to quantify total immunofluorescence staining per relevant area (spinal cord, cortex, or hippocampus) for each section, using a method by Barbero-Camps and colleagues to quantify immunofluorescence [124].

\section{Immunohistochemistry and image analysis}

Brain and lumbar spinal cord tissue was paraffin processed and sectioned at a $10 \mu \mathrm{m}$ thickness and the same brain plate and spinal cord regions used in the immunofluorescence analysis were used. Immunohistochemistry was performed on equidistant sections from the lumbar spinal cord $(\mathrm{n} \geq 4$ sections per animal) and hemibrain $(\mathrm{n} \geq 4$ sections per animal) using anti-NeuN (1:1000, Millipore). Sections were incubated in primary antibody overnight at $4^{\circ} \mathrm{C}$, incubated with horseradish peroxidaselabeled secondary antibody and stained with DAB. The number of positively-stained neurons with a clearly identifiable nucleus were quantified by a blinded observer using NIH Image J software to determine the number of alpha motor neurons in the ventral horn of the spinal cord as well as neurons in the cortex. For the hippocampus, a $200 \mu \mathrm{m} \times 1000 \mu \mathrm{m}$ rectangular region of the CA3 and CA1 was quantified manually [52].

\section{Western blot and dot blot analysis}

Spinal cord, hippocampus, and cortex samples from both RIPA and sarkosyl extractions were resolved by SDSPAGE or dot blot. Blots were probed with tau antibodies [TAU5, (1:1000), AT8 (1:1000), AT100 (1:1000) and AT180 (1:250)], and autophagy-related antibodies (antiLC3, 1:500, Novus Biologicals; anti-p62, 1:1000, BD Biosciences). After overnight incubation at $4^{\circ} \mathrm{C}$, blots were incubated in horseradish peroxidase-labeled secondary antibodies and visualized with an ECL substrate kit (Amersham). Band densities were analyzed with $\mathrm{NIH}$ Image $J$ software and band values were normalized to glyceraldehyde-3-phosphate dehydrogenase (GAPDH). Dot blots were prepared by pipetting $1.2 \mathrm{ul}$ of each sample in each square of a nitrocellulose membrane and allowed to dry for 30 minutes. Blots were incubated with T22 (1:250), overnight at $4^{\circ} \mathrm{C}$ followed by incubation with a horseradish peroxidase-labeled secondary and visualization with ECL. Dot intensities were analyzed with NIH Image J software.

\section{Statistical analysis}

A Student's t-test was used to compare exercised and sedentary P301S mice. A two-way ANOVA was used to compare all four groups (Tg-EX, Tg-SED, NTg-EX, and NTg-SED). After the ANOVA, a Newman-Keuls post-hoc (for behavioral tests; [125]) or Tukey's HSD post-hoc was used to compare the significant effects between groups. All results are displayed as mean \pm SEM.

\section{Abbreviations}

AD: Alzheimer's disease; CNS: Central nervous system; NFT: Neurofibrillary tangle; Aß: Amyloid beta; NTg: Non-transgenic; Tg: Transgenic; EX: Exercised; 
SED: Sedentary; LC3: Microtubule-associated protein 1A/1B light chain 3; p62/SQSTM1: p62/sequestosome 1; CA3: Cornus ammonis 3; CA1: Cornus ammonis 1.

\section{Competing interests}

The authors declare that they have no competing interests.

\section{Authors' contributions}

OON, JLE, and YSL designed the studies and OON and JLE wrote the manuscript; OON and SM performed experiments. The final manuscript was read and approved by all authors.

\section{Acknowledgements}

Research reported in this publication was supported by NIND of the National Institutes of Health under award number 1R21NS057651 (J.L.E) and by NIA of the National Institutes of Health under award number 1R15AG039008 (J.L.E).

\section{Author details}

${ }^{1}$ Department of Pharmacological and Pharmaceutical Sciences, University of Houston, 521 Science and Research Building 2, 4800 Calhoun Road, Houston, TX 77204, USA. ${ }^{2}$ American Association of Colleges of Pharmacy, Alexandria, VA 22314, USA.

Received: 22 April 2014 Accepted: 17 November 2014 Published: 28 November 2014

\section{References}

1. Prince $M$, Bryce R, Albanese E, Wimo A, Ribeiro W, Ferri CP: The global prevalence of dementia: a systematic review and metaanalysis. Alzheimers Dement 2013, 9:63-75. e62.

2. Hebert LE, Weuve J, Scherr PA, Evans DA: Alzheimer disease in the United States (2010-2050) estimated using the 2010 census. Neurology 2013, 80:1778-1783

3. Goedert M, Jakes R: Mutations causing neurodegenerative tauopathies. Biochim Biophys Acta 2005, 1739:240-250.

4. Hasegawa M: Biochemistry and molecular biology of tauopathies. Neuropathology 2006, 26:484-490.

5. Goedert M, Spillantini MG: Pathogenesis of the tauopathies. J Mol Neurosci 2011, 45:425-431.

6. Karakaya T, Fusser F, Prvulovic D, Hampel H: Treatment options for tauopathies. Curr Treat Options Neurol 2012, 14:126-136.

7. Anand R, Gill KD, Mahdi AA: Therapeutics of Alzheimer's disease: past, present and future. Neuropharmacology 2014, 76 Pt A:27-50.

8. Kramer AF, Colcombe SJ, McAuley E, Scalf PE, Erickson Kl: Fitness, aging and neurocognitive function. Neurobiol Aging 2005, 26(Suppl 1):124-127.

9. Lista I, Sorrentino G: Biological mechanisms of physical activity in preventing cognitive decline. Cell Mol Neurobiol 2010, 30:493-503.

10. Hogan CL, Mata J, Carstensen LL: Exercise holds immediate benefits for affect and cognition in younger and older adults. Psychol Aging 2013, 28:587-594.

11. Hotting K, Roder B: Beneficial effects of physical exercise on neuroplasticity and cognition. Neurosci Biobehav Rev 2013, 9 Pt B:2243-2257.

12. Winter B, Breitenstein C, Mooren FC, Voelker K, Fobker M, Lechtermann A, Krueger K, Fromme A, Korsukewitz C, Floel A, Knecht S: High impact running improves learning. Neurobiol Learn Mem 2007, 87:597-609.

13. Seifert $T$, Brassard $P$, Wissenberg $M$, Rasmussen $P$, Nordby $P$, Stallknecht $B$, Adser $H$, Jakobsen $A H$, Pilegaard $H$, Nielsen $H B$, Secher $\mathrm{NH}$ : Endurance training enhances BDNF release from the human brain. Am J Physiol Regul Integr Comp Physiol 2010, 298:R372-R377.

14. Gons RA, Tuladhar AM, de Laat KF, van Norden AG, van Dijk EJ, Norris DG, Zwiers MP, de Leeuw FE: Physical activity is related to the structural integrity of cerebral white matter. Neurology 2013, 81:971-976.

15. Tseng BY, Uh J, Rossetti HC, Cullum CM, Diaz-Arrastia RF, Levine BD, Lu H, Zhang R: Masters athletes exhibit larger regional brain volume and better cognitive performance than sedentary older adults. J Magn Reson Imaging 2013, 38:1169-1176.

16. Rolland Y, Pillard F, Klapouszczak A, Reynish E, Thomas D, Andrieu S, Riviere $D$, Vellas B: Exercise program for nursing home residents with Alzheimer's disease: a 1-year randomized, controlled trial. J Am Geriatr Soc 2007, 55:158-165.
17. Pitkala KH, Poysti MM, Laakkonen ML, Tilvis RS, Savikko N, Kautiainen $\mathrm{H}$ Strandberg TE: Effects of the Finnish Alzheimer disease exercise trial (FINALEX): a randomized controlled trial. JAMA Intern Med 2013, 173:894-901.

18. de Andrade LP, Gobbi LT, Coelho FG, Christofoletti G, Riani Costa JL, Stella F: Benefits of multimodal exercise intervention for postural control and frontal cognitive functions in individuals with Alzheimer's disease: a controlled trial. J Am Geriatr Soc 2013, 61:1919-1926.

19. Adlard PA, Perreau VM, Pop V, Cotman CW: Voluntary exercise decreases amyloid load in a transgenic model of Alzheimer's disease. J Neurosci 2005, 25:4217-4221.

20. Nichol KE, Poon WW, Parachikova Al, Cribbs DH, Glabe CG, Cotman CW: Exercise alters the immune profile in $\mathrm{Tg} 2576$ Alzheimer mice toward a response coincident with improved cognitive performance and decreased amyloid. I Neuroinflammation 2008, 5:13.

21. Um HS, Kang EB, Leem YH, Cho IH, Yang CH, Chae KR, Hwang DY, Cho JY: Exercise training acts as a therapeutic strategy for reduction of the pathogenic phenotypes for Alzheimer's disease in an NSE/APPswtransgenic model. Int J Mol Med 2008, 22:529-539.

22. Nichol KE, Parachikova Al, Cotman CW: Three weeks of running wheel exposure improves cognitive performance in the aged Tg2576 mouse. Behav Brain Res 2007, 184:124-132.

23. Yuede CM, Zimmerman SD, Dong H, Kling MJ, Bero AW, Holtzman DM, Timson BF, Csernansky JG: Effects of voluntary and forced exercise on plaque deposition, hippocampal volume, and behavior in the Tg2576 mouse model of Alzheimer's disease. Neurobiol Dis 2009, 35:426-432.

24. Nichol K, Deeny SP, Seif J, Camaclang K, Cotman CW: Exercise improves cognition and hippocampal plasticity in APOE epsilon4 mice. Alzheimers Dement 2009, 5:287-294.

25. Dao AT, Zagaar MA, Salim S, Eriksen JL, Alkadhi KA: Regular exercise prevents non-cognitive disturbances in a rat model of Alzheimer's disease. Int J Neuropsychopharmacol 2014, 17:593-602.

26. Steffen TM, Boeve BF, Mollinger-Riemann LA, Petersen CM: Long-term locomotor training for gait and balance in a patient with mixed progressive supranuclear palsy and corticobasal degeneration. Phys Ther 2007, 87:1078-1087.

27. Steffen TM, Boeve BF, Petersen CM, Dvorak L, Kantarci K: Long-term exercise training for an individual with mixed corticobasal degeneration and progressive supranuclear palsy features: 10-year case report follow-up. Phys Ther 2014, 94:289-296.

28. Leem YH, Lim HJ, Shim SB, Cho JY, Kim BS, Han PL: Repression of tau hyperphosphorylation by chronic endurance exercise in aged transgenic mouse model of tauopathies. J Neurosci Res 2009, 87:2561-2570.

29. Belarbi K, Burnouf S, Fernandez-Gomez FJ, Laurent C, Lestavel S, Figeac M, Sultan A, Troquier L, Leboucher A, Caillierez R, Grosjean ME, Demeyer D, Obriot H, Brion I, Barbot B, Galas MC, Staels B, Humez S, Sergeant N, Schraen-Maschke S, Muhr-Tailleux A, Hamdane M, Buée L: Beneficial effects of exercise in a transgenic mouse model of Alzheimer's disease-like Tau pathology. Neurobiol Dis 2011, 43:486-494.

30. Kang EB, Kwon IS, Koo JH, Kim EJ, Kim CH, Lee J, Yang CH, Lee Yl, Cho IH, Cho JY: Treadmill exercise represses neuronal cell death and inflammation during Abeta-induced ER stress by regulating unfolded protein response in aged presenilin 2 mutant mice. Apoptosis 2013, 18:1332-1347.

31. Souza LC, Filho CB, Goes AT, Fabbro LD, de Gomes MG, Savegnago L, Oliveira MS, Jesse CR: Neuroprotective effect of physical exercise in a mouse model of Alzheimer's disease induced by beta-amyloid(1)(-)(4)(0) peptide. Neurotox Res 2013, 24:148-163.

32. Dao AT, Zagaar MA, Levine AT, Salim S, Eriksen JL, Alkadhi KA: Treadmill exercise prevents learning and memory impairment in Alzheimer's disease-like pathology. Curr Alzheimer Res 2013, 10:507-515.

33. Liu HL, Zhao G, Zhang H, Shi LD: Long-term treadmill exercise inhibits the progression of Alzheimer's disease-like neuropathology in the hippocampus of APP/PS1 transgenic mice. Behav Brain Res 2013, 256:261-272.

34. Liu HL, Zhao G, Cai K, Zhao HH, Shi LD: Treadmill exercise prevents decline in spatial learning and memory in APP/PS1 transgenic mice through improvement of hippocampal long-term potentiation. Behav Brain Res 2011, 218:308-314.

35. Um HS, Kang EB, Koo JH, Kim HT, Jin L, Kim EJ, Yang CH, An GY, Cho $\mathrm{H}_{\text {, }}$ Cho JY: Treadmill exercise represses neuronal cell death in an aged transgenic mouse model of Alzheimer's disease. Neurosci Res 2011 69:161-173.

36. Cracchiolo JR, Mori T, Nazian SJ, Tan J, Potter H, Arendash GW: Enhanced cognitive activity-over and above social or physical activity-is required 
to protect Alzheimer's mice against cognitive impairment, reduce Abeta deposition, and increase synaptic immunoreactivity. Neurobiol Learn Mem 2007, 88:277-294.

37. Shim SB, Lim HJ, Chae KR, Kim CK, Hwang DY, Jee SW, Lee SH, Sin JS, Leem YH, Lee SH, Cho JS, Lee HH, Choi SY, Kim YK: Tau overexpression in transgenic mice induces glycogen synthase kinase 3 beta and beta-catenin phosphorylation. Neuroscience 2007, 146:730-740.

38. He C, Sumpter R Jr, Levine B: Exercise induces autophagy in peripheral tissues and in the brain. Autophagy 2012, 8:1548-1551.

39. Schaeffer V, Lavenir I, Ozcelik S, Tolnay M, Winkler DT, Goedert M: Stimulation of autophagy reduces neurodegeneration in a mouse model of human tauopathy. Brain 2012, 135:2169-2177.

40. Ozcelik S, Fraser G, Castets P, Schaeffer V, Skachokova Z, Breu K, Clavaguera F, Sinnreich M, Kappos L, Goedert M, Tolnay M, Winkler DT: Rapamycin attenuates the progression of tau pathology in P301S tau transgenic mice. PLoS One 2013, 8:e62459

41. Naylor M, Bowen KK, Sailor KA, Dempsey RJ, Vemuganti R: Preconditioninginduced ischemic tolerance stimulates growth factor expression and neurogenesis in adult rat hippocampus. Neurochem Int 2005, 47:565-572.

42. Molteni R, Ying Z, Gomez-Pinilla F: Differential effects of acute and chronic exercise on plasticity-related genes in the rat hippocampus revealed by microarray. Eur J Neurosci 2002, 16:1107-1116.

43. Huang AM, Jen CJ, Chen HF, Yu L, Kuo YM, Chen HI: Compulsive exercise acutely upregulates rat hippocampal brain-derived neurotrophic factor. J Neural Transm 2006, 113:803-811.

44. Gomez-Pinilla F, Ying Z, Roy RR, Molteni R, Edgerton VR: Voluntary exercise induces a BDNF-mediated mechanism that promotes neuroplasticity. J Neurophysiol 2002, 88:2187-2195.

45. Marlatt MW, Potter MC, Lucassen PJ, van Praag H: Running throughout middle-age improves memory function, hippocampal neurogenesis, and BDNF levels in female C57BL/6 J mice. Dev Neurobiol 2012, 72:943-952.

46. Parachikova A, Nichol KE, Cotman CW: Short-term exercise in aged Tg2576 mice alters neuroinflammation and improves cognition. Neurobiol Dis 2008, 30:121-129.

47. Ke HC, Huang HJ, Liang KC, Hsieh-Li HM: Selective improvement of cognitive function in adult and aged APP/PS1 transgenic mice by continuous nonshock treadmill exercise. Brain Res 2011, 1403:1-11.

48. Garcia-Mesa Y, Lopez-Ramos JC, Gimenez-Llort L, Revilla S, Guerra R, Gruart A, Laferla FM, Cristofol R, Delgado-Garcia JM, Sanfeliu C: Physical exercise protects against Alzheimer's disease in 3xTg-AD mice. J Alzheimers Dis 2011, 24:421-454

49. Xu ZQ, Zhang LQ, Wang Q, Marshall C, Xiao N, Gao JY, Wu T, Ding J, Hu G, Xiao M: Aerobic exercise combined with antioxidative treatment does not counteract moderate- or mid-stage Alzheimer-like pathophysiology of APP/PS1 mice. CNS Neurosci Ther 2013, 19:795-803.

50. Garcia-Mesa Y, Gimenez-Llort L, Lopez LC, Venegas C, Cristofol R, Escames G, Acuna-Castroviejo D, Sanfeliu C: Melatonin plus physical exercise are highly neuroprotective in the 3xTg-AD mouse. Neurobiol Aging 2012 33:1124. e1113-1129.

51. Leem YH, Lee Yl, Son HJ, Lee SH: Chronic exercise ameliorates the neuroinflammation in mice carrying NSE/htau23. Biochem Biophys Res Commun 2011, 406:359-365.

52. Yoshiyama Y, Higuchi M, Zhang B, Huang SM, Iwata N, Saido TC, Maeda J, Suhara T, Trojanowski JQ, Lee VM: Synapse loss and microglial activation precede tangles in a P301S tauopathy mouse model. Neuron 2007, 53:337-351.

53. Lau YS, Patki G, Das-Panja K, Le WD, Ahmad SO: Neuroprotective effects and mechanisms of exercise in a chronic mouse model of Parkinson's disease with moderate neurodegeneration. Eur J Neurosci 2011, 33:1264-1274.

54. Patki G, Lau YS: Impact of exercise on mitochondrial transcription factor expression and damage in the striatum of a chronic mouse model of Parkinson's disease. Neurosci Lett 2011, 505:268-272.

55. Planel E, Bretteville A, Liu L, Virag L, Du AL, Yu WH, Dickson DW, Whittington RA, Duff KE: Acceleration and persistence of neurofibrillary pathology in a mouse model of tauopathy following anesthesia. FASEB J 2009, 23:2595-2604.

56. Mizushima N, Yoshimori T: How to interpret LC3 immunoblotting. Autophagy 2007, 3:542-545.

57. Norman JM, Cohen GM, Bampton ET: The in vitro cleavage of the hAtg proteins by cell death proteases. Autophagy 2010, 6:1042-1056.

58. El-Khoury V, Pierson S, Szwarcbart E, Brons NH, Roland O, Cherrier-De Wilde S, Plawny L, Van Dyck E, Berchem G: Disruption of autophagy by the histone deacetylase inhibitor MGCD0103 and its therapeutic implication in B-cell chronic lymphocytic leukemia. Leukemia 2014, 28:1636-1646.

59. Bugiani O, Murrell JR, Giaccone G, Hasegawa M, Ghigo G, Tabaton M, Morbin M, Primavera A, Carella F, Solaro C, Grisoli M, Savoiardo M, Spillantini MG, Tagliavini F, Goedert M, Ghetti B: Frontotemporal dementia and corticobasal degeneration in a family with a P301S mutation in tau. J Neuropathol Exp Neurol 1999, 58:667-677.

60. Lossos A, Reches A, Gal A, Newman JP, Soffer D, Gomori JM, Boher M, Ekstein D, Biran I, Meiner Z, Abramsky O, Rosenmann H: Frontotemporal dementia and parkinsonism with the P301S tau gene mutation in a Jewish family. J Neurol 2003, 250:733-740.

61. Goedert M, Jakes R, Crowther RA: Effects of frontotemporal dementia FTDP-17 mutations on heparin-induced assembly of tau filaments. FEBS Lett 1999, 450:306-311.

62. Scattoni ML, Gasparini L, Alleva E, Goedert M, Calamandrei G, Spillantini MG: Early behavioural markers of disease in P301S tau transgenic mice. Behav Brain Res 2010, 208:250-257.

63. Iba M, Guo JL, McBride JD, Zhang B, Trojanowski JQ, Lee VM: Synthetic tau fibrils mediate transmission of neurofibrillary tangles in a transgenic mouse model of Alzheimer's-like tauopathy. J Neurosci 2013, 33:1024-1037.

64. Maruyama M, Shimada H, Suhara T, Shinotoh H, Ji B, Maeda J, Zhang MR, Trojanowski JQ, Lee VM, Ono M, Masamoto K, Takano H, Sahara N, Iwata N, Okamura N, Furumoto S, Kudo Y, Chang Q, Saido TC, Takashima A, Lewis J, Jang MK, Aoki I, Ito H, Higuchi M: Imaging of tau pathology in a tauopathy mouse model and in Alzheimer patients compared to normal controls. Neuron 2013, 79:1094-1108

65. Zhang B, Carroll J, Trojanowski JQ, Yao Y, Iba M, Potuzak JS, Hogan AM, Xie SX, Ballatore C, Smith AB 3rd, Lee VM, Brunden KR: The microtubule-stabilizing agent, epothilone $D$, reduces axonal dysfunction, neurotoxicity, cognitive deficits, and Alzheimer-like pathology in an interventional study with aged tau transgenic mice. J Neurosci 2012, 32:3601-3611.

66. Hoffmann NA, Dorostkar MM, Blumenstock S, Goedert M, Herms J: Impaired plasticity of cortical dendritic spines in P301S tau transgenic mice. Acta Neuropathol Commun 2013, 1:82

67. Macias M, Nowicka D, Czupryn A, Sulejczak D, Skup M, Skangiel-Kramska J, Czarkowska-Bauch J: Exercise-induced motor improvement after complete spinal cord transection and its relation to expression of brain-derived neurotrophic factor and presynaptic markers. BMC Neurosci 2009, 10:144

68. Toy WA, Petzinger GM, Leyshon BJ, Akopian GK, Walsh JP, Hoffman MV, Vuckovic MG, Jakowec MW: Treadmill exercise reverses dendritic spine loss in direct and indirect striatal medium spiny neurons in the 1-methyl-4-phenyl-1,2,3,6-tetrahydropyridine (MPTP) mouse model of Parkinson's disease. Neurobiol Dis 2014, 63:201-209.

69. Quirie A, Hervieu M, Garnier P, Demougeot C, Mossiat C, Bertrand N, Martin A Marie C, Prigent-Tessier A: Comparative effect of treadmill exercise on mature BDNF production in control versus stroke rats. PLoS One 2012, 7:e44218.

70. Garcia PC, Real CC, Ferreira AF, Alouche SR, Britto LR, Pires RS: Different protocols of physical exercise produce different effects on synaptic and structural proteins in motor areas of the rat brain. Brain Res 2012, 1456:36-48.

71. Ding Y, Li J, Lai Q, Azam S, Rafols JA, Diaz FG: Functional improvement after motor training is correlated with synaptic plasticity in rat thalamus. Neurol Res 2002, 24:829-836.

72. Di Loreto S, Falone S, D'Alessandro A, Santini S Jr, Sebastiani P, Cacchio M, Amicarelli F: Regular and moderate exercise initiated in middle age prevents age-related amyloidogenesis and preserves synaptic and neuroprotective signaling in mouse brain cortex. Exp Gerontol 2014, 57C:57-65.

73. Ferreira AF, Real CC, Rodrigues AC, Alves AS, Britto LR: Short-term, moderate exercise is capable of inducing structural, BDNF-independent hippocampal plasticity. Brain Res 2011, 1425:111-122.

74. Fang ZH, Lee $\mathrm{CH}$, Seo MK, Cho H, Lee JG, Lee BJ, Park SW, Kim YH: Effect of treadmill exercise on the BDNF-mediated pathway in the hippocampus of stressed rats. Neurosci Res 2013, 76:187-194.

75. Shih PC, Yang YR, Wang RY: Effects of exercise intensity on spatial memory performance and hippocampal synaptic plasticity in transient brain ischemic rats. PLoS One 2013, 8:e78163.

76. Augustinack JC, Schneider A, Mandelkow EM, Hyman BT: Specific tau phosphorylation sites correlate with severity of neuronal cytopathology in Alzheimer's disease. Acta Neuropathol 2002, 103:26-35. 
77. Koga S, Kojima A, Ishikawa C, Kuwabara S, Arai K, Yoshiyama Y: Effects of diet-induced obesity and voluntary exercise in a tauopathy mouse model: implications of persistent hyperleptinemia and enhanced astrocytic leptin receptor expression. Neurobiol Dis 2014, 71:180-192.

78. Marlatt MW, Potter MC, Bayer TA, van Praag H, Lucassen PJ: Prolonged running, not fluoxetine treatment, increases neurogenesis, but does not alter neuropathology, in the 3xTg mouse model of Alzheimer's disease. Curr Top Behav Neurosci 2013, 15:313-340.

79. Leasure $J \mathrm{~L}$, Jones $\mathrm{M}$ : Forced and voluntary exercise differentially affect brain and behavior. Neuroscience 2008, 156:456-465.

80. Julien C, Bretteville A, Planel E: Biochemical isolation of insoluble tau in transgenic mouse models of tauopathies. Methods Mol Biol 2012, 849:473-491.

81. Lasagna-Reeves CA, Castillo-Carranza DL, Sengupta U, Guerrero-Munoz MJ, Kiritoshi T, Neugebauer $V$, Jackson GR, Kayed R: Alzheimer brain-derived tau oligomers propagate pathology from endogenous tau. Sci Rep 2012 2:700.

82. Gerson JE, Kayed R: Formation and propagation of tau oligomeric seeds. Front Neurol 2013, 4:93.

83. Crescenzi R, DeBrosse C, Nanga RP, Reddy S, Haris M, Hariharan H, Iba M, Lee VM, Detre JA, Borthakur A, Reddy R: In vivo measurement of glutamate loss is associated with synapse loss in a mouse model of tauopathy. Neuroimage 2014, 101:185-192.

84. van Groen T, Miettinen P, Kadish I: The entorhinal cortex of the mouse: organization of the projection to the hippocampal formation. Hippocampus 2003, 13:133-149.

85. Witter MP, Wouterlood FG, Naber PA, Van Haeften T: Anatomical organization of the parahippocampal-hippocampal network. Ann N Y Acad Sci 2000, 911:1-24.

86. de Calignon A, Polydoro M, Suarez-Calvet M, William C, Adamowicz DH, Kopeikina KJ, Pitstick R, Sahara N, Ashe KH, Carlson GA, Spires-Jones TL, Hyman BT: Propagation of tau pathology in a model of early Alzheimer's disease. Neuron 2012, 73:685-697.

87. Liu L, Drouet V, Wu JW, Witter MP, Small SA, Clelland C, Duff K: Trans-synaptic spread of tau pathology in vivo. PLoS One 2012, 7:e31302.

88. Maurin $\mathrm{H}$, Chong SA, Kraev I, Davies H, Kremer A, Seymour CM, Lechat $B$, Jaworski T, Borghgraef P, Devijver H, Callewaert G, Stewart MG, Van Leuven F: Early structural and functional defects in synapses and myelinated axons in stratum lacunosum moleculare in two preclinical models for tauopathy. PLoS One 2014, 9:e87605.

89. Poduri A, Beason-Held LL, Moss MB, Rosene DL, Hyman BT: CA3 neuronal degeneration follows chronic entorhinal cortex lesions. Neurosci Lett 1995 197:1-4

90. Ke Z, Yip SP, Li L, Zheng XX, Tong KY: The effects of voluntary, involuntary, and forced exercises on brain-derived neurotrophic factor and motor function recovery: a rat brain ischemia model. PLOS One 2011, 6:e16643.

91. Sennott J, Morrissey J, Standley PR, Broderick TL: Treadmill exercise training fails to reverse defects in glucose, insulin and muscle GLUT4 content in the $\mathrm{db} / \mathrm{db}$ mouse model of diabetes. Pathophysiol J Int Soc Pathophysiol 2008, 15:173-179.

92. Cook MD, Martin SA, Williams C, Whitlock K, Wallig MA, Pence BD, Woods JA: Forced treadmill exercise training exacerbates inflammation and causes mortality while voluntary wheel training is protective in a mouse model of colitis. Brain Behav Immun 2013, 33:46-56.

93. Mokhtarian A, Lefaucheur JP, Even PC, Sebille A: Effects of treadmill exercise and high-fat feeding on muscle degeneration in mdx mice at the time of weaning. Clin Sci 1995, 89:447-452.

94. McKinnon C, Tabrizi SJ: The ubiquitin-proteasome system in neurodegeneration. Antioxid Redox Signal 2014.

95. Tan CC, Yu JT, Tan MS, Jiang T, Zhu XC, Tan L: Autophagy in aging and neurodegenerative diseases: implications for pathogenesis and therapy. Neurobiol Aging 2013, 35:941-957.

96. Bjorkoy G, Lamark T, Pankiv S, Overvatn A, Brech A, Johansen T: Monitoring autophagic degradation of p62/SQSTM1. Methods Enzymol 2009, 452:181-197.

97. Schaeffer $V$, Goedert M: Stimulation of autophagy is neuroprotective in a mouse model of human tauopathy. Autophagy 2012, 8:1686-1687.

98. Spilman P, Podlutskaya N, Hart MJ, Debnath J, Gorostiza O, Bredesen D, Richardson A, Strong R, Galvan V: Inhibition of mTOR by rapamycin abolishes cognitive deficits and reduces amyloid-beta levels in a mouse model of Alzheimer's disease. PLoS One 2010, 5:e9979.
99. Sarkar S, Perlstein EO, Imarisio S, Pineau S, Cordenier A, Maglathlin RL, Webster JA, Lewis TA, O'Kane CJ, Schreiber SL, Rubinsztein DC: Small molecules enhance autophagy and reduce toxicity in Huntington's disease models. Nat Chem Biol 2007, 3:331-338.

100. Sarkar S, Davies JE, Huang Z, Tunnacliffe A, Rubinsztein DC: Trehalose, a novel mTOR-independent autophagy enhancer, accelerates the clearance of mutant huntingtin and alpha-synuclein. J Biol Chem 2007, 282:5641-5652.

101. Webb JL, Ravikumar B, Atkins J, Skepper JN, Rubinsztein DC: Alpha-Synuclein is degraded by both autophagy and the proteasome. J Biol Chem 2003, 278:25009-25013.

102. Babu JR, Geetha T, Wooten MW: Sequestosome 1/p62 shuttles polyubiquitinated tau for proteasomal degradation. J Neurochem 2005, 94:192-203.

103. Ramesh Babu J, Lamar Seibenhener M, Peng J, Strom AL, Kemppainen R, Cox N, Zhu H, Wooten MC, Diaz-Meco MT, Moscat J, Wooten MW: Genetic inactivation of p62 leads to accumulation of hyperphosphorylated tau and neurodegeneration. J Neurochem 2008, 106:107-120.

104. Lee MJ, Lee JH, Rubinsztein DC: Tau degradation: the ubiquitin-proteasome system versus the autophagy-lysosome system. Prog Neurobio/ 2013 105:49-59.

105. Ambegaokar SS, Jackson GR: The downward spiral of tau and autolysosomes: a new hypothesis in neurodegeneration. Autophagy 2012, 8:1144-1145.

106. Elrick MJ, Lieberman AP: Autophagic dysfunction in a lysosomal storage disorder due to impaired proteolysis. Autophagy 2013, 9:234-235.

107. Lee $J H$, Yu WH, Kumar A, Lee S, Mohan PS, Peterhoff CM, Wolfe DM, Martinez-Vicente M, Massey AC, Sovak G, Uchiyama Y, Westaway D, Cuervo AM, Nixon RA: Lysosomal proteolysis and autophagy require presenilin 1 and are disrupted by Alzheimer-related PS1 mutations. Cell 2010, 141:1146-1158.

108. Nixon RA, Yang DS: Autophagy failure in Alzheimer's disease-locating the primary defect. Neurobiol Dis 2011, 43:38-45.

109. Pickford F, Masliah E, Britschgi M, Lucin K, Narasimhan R, Jaeger PA, Small S, Spencer B, Rockenstein E, Levine B, Wyss-Coray T: The autophagy-related protein beclin 1 shows reduced expression in early Alzheimer disease and regulates amyloid beta accumulation in mice. J Clin Invest 2008, 118:2190-2199.

110. Rasmussen P, Brassard P, Adser H, Pedersen MV, Leick L, Hart E, Secher NH, Pedersen BK, Pilegaard $\mathrm{H}$ : Evidence for a release of brain-derived neurotrophic factor from the brain during exercise. Exp Physiol 2009, 94:1062-1069.

111. Berchtold NC, Chinn G, Chou M, Kesslak JP, Cotman CW: Exercise primes a molecular memory for brain-derived neurotrophic factor protein induction in the rat hippocampus. Neuroscience 2005, 133:853-861.

112. Chen MJ, Russo-Neustadt AA: Running exercise-induced up-regulation of hippocampal brain-derived neurotrophic factor is CREB-dependent. Hippocampus 2009, 19:962-972

113. Neeper SA, Gomez-Pinilla F, Choi J, Cotman C: Exercise and brain neurotrophins. Nature 1995, 373:109.

114. Neeper SA, Gomez-Pinilla F, Choi J, Cotman CW: Physical activity increases mRNA for brain-derived neurotrophic factor and nerve growth factor in rat brain. Brain Res 1996, 726:49-56.

115. Reichardt LF: Neurotrophin-regulated signalling pathways. Philos Trans $R$ Soc Lond B Biol Sci 2006, 361:1545-1564.

116. Elliott $E$, Atlas R, Lange A, Ginzburg I: Brain-derived neurotrophic factor induces a rapid dephosphorylation of tau protein through a PI-3 Kinase signalling mechanism. Eur J Neurosci 2005, 22:1081-1089.

117. Dobarro M, Orejana L, Aguirre N, Ramirez MJ: Propranolol restores cognitive deficits and improves amyloid and Tau pathologies in a senescence-accelerated mouse model. Neuropharmacology 2013, 64:137-144.

118. Bayod S, Del Valle J, Canudas AM, Lalanza JF, Sanchez-Roige S, Camins A Escorihuela RM, Pallas M: Long-term treadmill exercise induces neuroprotective molecular changes in rat brain. J Appl Physiol 2011, 111:1380-1390

119. Al-Jarrah M, Pothakos K, Novikova L, Smirnova IV, Kurz MJ, Stehno-Bittel L, Lau YS: Endurance exercise promotes cardiorespiratory rehabilitation without neurorestoration in the chronic mouse model of parkinsonism with severe neurodegeneration. Neuroscience 2007, 149:28-37.

120. Vollert C, Zagaar M, Hovatta I, Taneja M, Vu A, Dao A, Levine A, Alkadhi K, Salim S: Exercise prevents sleep deprivation-associated anxiety-like behavior in rats: potential role of oxidative stress mechanisms. Behav Brain Res 2011, 224:233-240. 
121. Lasagna-Reeves CA, Castillo-Carranza DL, Sengupta U, Sarmiento J, Troncoso J, Jackson GR, Kayed R: Identification of oligomers at early stages of tau aggregation in Alzheimer's disease. FASEB J 2012, 26:1946-1959.

122. Franklin KBJ, Paxinos G: Paxinos and Franklin's the mouse brain in stereotaxic coordinates. Compact 3rd ed. Edited by Franklin KBJ, Paxinos G. Amsterdam; London: Elsevier Academic Press; 2008.

123. Watson C: The spinal cord : a Christopher and Dana Reeve Foundation text and atlas. London: Academic; 2009.

124. Barbero-Camps E, Fernandez A, Martinez L, Fernandez-Checa JC, Colell A: APP/PS1 mice overexpressing SREBP-2 exhibit combined Abeta accumulation and tau pathology underlying Alzheimer's disease. Hum Mol Genet 2013, 22:3460-3476.

125. Bailey KR, Crawley JN: Anxiety-Related Behaviors in Mice. In Methods of Behavior Analysis in Neuroscience. 2nd edition. Edited by Buccafusco J. Boca Raton (FL): Frontiers in Neuroscience; 2009.

doi:10.1186/1750-1326-9-54

Cite this article as: Ohia-Nwoko et al.: Long-term treadmill exercise attenuates tau pathology in P301S tau transgenic mice. Molecular

Neurodegeneration 2014 9:54.

\section{Submit your next manuscript to BioMed Central and take full advantage of:}

- Convenient online submission

- Thorough peer review

- No space constraints or color figure charges

- Immediate publication on acceptance

- Inclusion in PubMed, CAS, Scopus and Google Scholar

- Research which is freely available for redistribution 